Research Article

\title{
Vitamin D Deficiency and its Association with Nephropathy in Type 2 Diabetes Mellitus Patients: A Cross Sectional Study
}

Satish Kumar', Virendra Atam ${ }^{2}$, Satyendra Kumar Sonkar ${ }^{3}$, Ved Prakash ${ }^{4}$, Amit Kumar ${ }^{5}$, Ajay Kumar ${ }^{6}$, Mohammad Kaifee ${ }^{7}$, KK Sawlani ${ }^{8}$

${ }^{1,5}$ Senior Resident, ${ }^{2}$ Professor and Head, ${ }^{3,8}$ Professor, ${ }^{6}$ Associate Professor, Department of Medicine, King George's Medical University, Lucknow, India.

${ }^{4}$ Professor and Head, ${ }^{7}$ Senior Resident, Department of Pulmonary and Critical Care Medicine, King George's Medical University, Lucknow, India.

DOI: https://doi.org/10.24321/2349.7181.201912

I $\quad \begin{array}{lllll}\mathbf{N} & \mathbf{F} & \mathbf{O}\end{array}$

Corresponding Author:

Satish Kumar, Department of Medicine, King George's Medical University, Lucknow, India.

E-mail Id:

dr.satishkgmu@gmail.com

Orcid Id:

https://orcid.org/0000-0002-6691-4281

How to cite this article:

Kumar S, Atam V, Sonkar SK, Prakash V, Kumar A, Kumar A et al. Vitamin D Deficiency and its Association with Nephropathy in Type 2 Diabetes Mellitus Patients: A Cross Sectional Study. J Adv Res Med 2019; 6(3): 1-7.

Date of Submission: 2019-09-07

Date of Acceptance: 2019-11-16
$\begin{array}{llllllll}\mathbf{A} & \mathbf{B} & \mathbf{S} & \mathbf{T} & \mathbf{R} & \mathbf{A} & \mathbf{C} & \mathbf{T}\end{array}$

Background: Vitamin D (VD) deficiency is linked to insulin activity and its release. It is associated with uncontrolled diabetes and more complications in diabetic patients. So, this study will prove importance of investigating serum VD level in Type 2 DM (T2DM) patients and its relation to complication of diabetic nephropathy.

Materials and Methods: Total 1025 patients with Type 2 diabetes were enrolled in this study. Age limit was from 40 to 76 year. Investigations for serum VD, haemoglobin A1c ( $\mathrm{HbA1c}$ ), high-sensitivity C-reactive protein (hs-CRP) and urinary Albumin: Creatinine Ratio (ACR) were done in each patient.

Result: It was found that most of the patient (77.89\%) were having VD $<29.88 \mathrm{ng} / \mathrm{m}$ along with significantly higher ACR and hs-CRP levels in these patients $(P=0.012$ and $P=0.007$, respectively). VD was observed significantly lesser in females than males $P<0.001$. Those patients who were exposed to sunrays had significantly more VD values and lesser hs-CRP values in comparison to less-exposed ones, P-value (0.001 and $<0.001)$, respectively. Physical activity significantly raises VD and decreases ACR levels in diabetic patients, P-value (0.045 and $0.001)$, respectively. Except age $(r=0.356 P=0.041)$ all other factors like $\mathrm{BMI}(r=-0.503 \mathrm{P}=0.008)$, duration of disease $(r=-0.489 \mathrm{P}=0.004), \mathrm{ACR}$ $(r=-0.295 \mathrm{P}=0.016)$ and $\mathrm{HbA1C}(r=-0.330 \mathrm{P}=0.031)$ were negatively correlated with VD.

Conclusion: This study concluded that Type 2 diabetes with VD deficiency are prone for the development of nephropathy.

Keywords: Type 2 Diabetes Mellitus, HbA1C, Vitamin D, Nephropathy, Albumin: Creatinine Ratio, High-Sensitivity C-Reactive Protein 


\section{Introduction}

In recent years Vitamin D(VD) is known for its antiproliferative, immunomodulatory, anti-inflammation and stimulating cell differentiation functions. ${ }^{1}$ So that, it plays major role in protection of body health with infections, malignancies, autoimmune disorders, respiratory and Cardiovascular Diseases (CVDs). ${ }^{2}$ Recently, it was also reported that VD is associated with the progression of Type 2 Diabetes Mellitus (T2DM), as VD has direct role in pancreatic $\beta$-cell activity, insulin release and action. ${ }^{3}$

VD deficiency is found in most of the part of the world. ${ }^{4,5}$ It is estimated that about 1 billion peoples have VD deficiency worldwide ${ }^{6}$ and $50 \%$ of the adults in developing countries have absence of VD. ${ }^{7}$ While in developed nations, the prevalence rate of VD deficiency is about $41.6 \% .{ }^{4}$ Factors associated with VD deficiency includes lesser sunlight exposure, dark skin, elderly, winter season, use of clothes covering most of the body, obesity and female gender. ${ }^{8,9}$ Occurrence of VD deficiency in Type 1 and T2DM is already proven by some studies. ${ }^{5}$ Studies done in Sudan also found correlation of VD deficiency and development of T2DM. VD deficiency is more common in female diabetics. ${ }^{10}$

VD inhibits the endothelial destruction in the kidney. Damage of endothelium causes Microalbuminuria (MAU), due to its role in negative regulation of renin-angiotensinaldosterone system. So many reports are there correlating between MAU and VD deficiency in T2DM. ${ }^{11}$ As VD deficiency increases, albuminuria aggravates. ${ }^{12}$

Early finding and correction of VD deficiency will prevent T2DM complications. So, the current study aimed to search whether VD has diagnostic and predictive role in defining nephropathy in T2DM subjects.

\section{Material and Methods}

This cross-sectional study was done on randomly selected subjects with confirmed diagnosis of Type 2 diabetes mellitus who were attending medicine outdoor patient department of King George's Medical University, Uttar Pradesh, India. Consent was taken from each subject and blood was investigated for 1025 clinically diagnosed subjects including of 470 males and 555 females. Excluded T2DM patients were those with pre-existing inflammation, renal diseases, cardiovascular diseases, liver diseases and those who were on VD supplementation. Diagnosis of T2DM was made on behalf of history, previous records, clinical examinations and investigations. Questions about the patient's age, sex, economic lifestyle, family history, education level and sunrays exposure were asked. Sugar status, BMI and VD values were compared for every subject. Those with Haemoglobin A1c (HbA1c) $\leq 8 \%$ were considered as sugar controlled and those with $>8 \%$ as sugar uncontrolled. BMI was classified as normal weight $18.5-25 \mathrm{~kg} / \mathrm{m}^{2}$ overweight $>25-30 \mathrm{~kg} / \mathrm{m}^{2}$ and obese $>30$ $\mathrm{kg} / \mathrm{m}^{2}{ }^{2}$ Meanwhile, VD values $\leq 30 \mathrm{ng} / \mathrm{ml}$ put as deficient and $>30 \mathrm{ng} / \mathrm{ml}$ as adequate.

This study was approved by the Local Ethical Committee of hospital. Written pre-informed consent was taken from each study participants.

\section{Calculation of BMI, VD, hsCRP, HbAIC and ACR Values}

- Body Mass Index (BMI) was measured by dividing body weight in kilograms by body height in meters square $\left(\mathrm{kg} / \mathrm{m}^{2}\right)$.

- Serum VD values were estimated by competitive inhibition enzyme-linked immunosorbent assay or ELISA.

- $\quad$ Serum levels of high-sensitivity C-reactive protein (hs-CRP) was estimated by the particle-enhanced immunoturbidimetric assay method Cobas C-311. Human CRP agglutinates with latex particles which are already lodged with monoclonal anti-CRP antibodies. The formed precipitate was estimated turbidimetrically.

- As per the manufacturer, urine albumin and creatinine were calculated by Cobas $\mathrm{C}-311^{\circ}$ fully automated analyser. Within the blood sample anti-albumin antibodies cross react with antigen and results in formation of antigen-antibody complexes which were analysed turbidimetrically. Reaction of creatinine to picrate in alkaline medium results in yellow-red product whose rate of synthesis is directly proportional to the creatinine value in the blood sample, which is further analysed by photometrically.

- HbA1c measurement was done in fully automated closed system - Roche Cobas C-311 ${ }^{\circ}$. Total haemoglobin and $\mathrm{HbA1C}$ values were calculated after haemolysis of the anticoagulated whole blood sample. Spectrophotometer analysed total haemoglobin while $\mathrm{HbA1c}$ was measured by immune turbidimetrically. The ratio of both above values resulted in the final percentage of $\mathrm{HbA} 1 \mathrm{c}$.

\section{Statistical Analysis}

Statistical analysis was performed using SPSS Statistics software. Base line characteristics were assessed with standard descriptive statistics. Data were presented in the form of frequencies, percentage, and means \pm standard deviation. The Student's $t$-test was used to compare mean levels of study parameters between groups. Categorical variables were compared using Chi-square and multiple regression tests. Pearson's correlation coefficient test used to calculate the correlation between continuous variables. $p<0.05$ was considered statistically significant. 


\section{Result}

\section{Demographic and Baseline Features of Study Participants}

Among total 1025 studied, 555 (54\%) were female and 470 (54\%) were male. 805 (78.5\%) had VD deficient while 220 (21.5\%) were having adequate VD. Maximum number of patients were with higher BMI values and were categorised in overweight $472(46 \%)$, obese $317(31 \%)$ and normal weight $236(23 \%)$ patients. Total $705(68.8 \%)$ subjects were with uncontrolled blood sugar level. Of all 1025 patients, $893(87.1 \%)$ were having sun bath of less than 5 hours. 534 (52.1\%) were having no any physical activity Table 1.

Table I.Demographic and baseline features of study participants

\begin{tabular}{|c|c|c|}
\hline $\begin{array}{l}\text { S. } \\
\text { No. }\end{array}$ & Characteristics & $\begin{array}{c}\text { Frequency } \\
\text { (\%) }\end{array}$ \\
\hline 1. & Male & $46 \%(470)$ \\
\hline 2. & Female & $54 \%(555)$ \\
\hline 3. & $<55$ years age & $47 \%(480)$ \\
\hline 4. & $>55$ years age & $53 \%(545)$ \\
\hline 5. & Normal weight & $23 \%(236)$ \\
\hline 6. & Overweight & $46 \%(472)$ \\
\hline 7. & obese & $31 \%(317)$ \\
\hline 8. & Controlled sugar & $31 \%(320)$ \\
\hline 9. & Uncontrolled sugar & $68.8 \%(705)$ \\
\hline 10. & Low qualification & $18 \%(185)$ \\
\hline 11. & Moderate qualification & $65 \%(666)$ \\
\hline 12. & High qualification & $17 \%(174)$ \\
\hline 13. & Low life style & $35 \%(359)$ \\
\hline 14. & Moderate life style & $57.40 \%(588)$ \\
\hline 15. & Good life style & $7.6 \%(78)$ \\
\hline 16. & Do physical exercise & $47.9 \%(491)$ \\
\hline 17. & Not do physical exercise & $52.1 \%(534)$ \\
\hline 18. & Sun exposure $<5$ hours & $87.1 \%(893)$ \\
\hline 19. & Sun exposure $<5$ hours & $12.9 \%(132)$ \\
\hline 20. & Family history of DM $1^{\text {st }}$ degree & $36.5 \%(374)$ \\
\hline 21. & Family history of DM $2^{\text {nd }}$ degree & $46.3 \%(474)$ \\
\hline 22. & No Family history of DM & $17.2 \%(176)$ \\
\hline 23. & Family history of CVD-Yes & $14.1 \%(145)$ \\
\hline 24. & Family history of CVD-No & $85.9 \%(880)$ \\
\hline 25. & On cholesterol lowering drug & $47.2 \%(484)$ \\
\hline 26. & Not on cholesterol lowering drug & $52.8 \%(541)$ \\
\hline 27. & VD deficient & $78.5 \%(805)$ \\
\hline 28. & VD sufficient & $21.5 \%(220)$ \\
\hline
\end{tabular}

DM: Diabetes Mellitus, CVD: Cardiovascular Disease.

\section{Association of Nonparametric Variables with Vitamin D Levels}

It was observed that $\mathrm{BMI}$, sex and sun exposure were significantly linked with VD deficiency $(P=0.004, P<0.001$ and $P=0.006$, respectively). Also these parameters increases the risk of VD deficiency (sex - Odd Ratio [OR]: 3.89 with Confidence Interval [Cl]: [1.89-7.98]; BMI - OR: 5.97 with $\mathrm{Cl}$ : [1.79-19.79]; and sun exposure - OR: 3.5 with $\mathrm{Cl}$ : [1.458.39]) (Table2).

It was observed that the mean values of hs-CRP and Albumin: Creatinine Ratio (ACR) were on higher side in T2DM patients with VD deficiency in comparison to patients with adequate VD. It was found significant $(P=0.007$ and $P=0.001$, respectively). However, the mean value of $\mathrm{HbA1c}$ was found non-significant in both groups. On comparing mean values of VD levels in males $(30.2 \pm 12.2 \mathrm{ng} / \mathrm{ml})$ and females $(20.0 \pm 8.90 \mathrm{ng} / \mathrm{ml})$ there was significant reduction in females with $P<0.001$, while hs-CRP $(5.91 \pm 2.61 \mathrm{mg} / \mathrm{l})$ was considerably raised $(3.54 \pm 2.55 \mathrm{mg} / \mathrm{l})$ with $P=0.004$.

Sun exposed patients with $<5$ hours were having significantly lower mean VD level $(23.6 \pm 11.2 \mathrm{ng} / \mathrm{ml})$ in comparison to other group with sun exposer $>5$ hours $(32.8 \pm 12.3 \mathrm{ng} / \mathrm{ml})$, $P=0.001$. hs-CRP was significantly raised in patients with $<5$ hours sun exposer $(5.15 \pm 6.48 \mathrm{mg} / \mathrm{l})$ than with $>5$ hours $(2.81 \pm 1.91 \mathrm{mg} / \mathrm{l})$ with $P<0.001$.

Raised VD and lesser ACR levels with $P=0.045$ and $P=0.002$, respectively, were observed in physically exercising subjects. Also results were found that T2DM patients with uncontrolled blood sugar levels were having significantly more ACR with $P=0.018$; the results were presented in Table 3.

Two tails Student's $t$-test has been employed to compare between variables. The results expressed as mean $\pm S D$, and $P<0.05$ was statistically considered significant. $V D=V i t a m i n$ $D ; \mathrm{HbA1c}=$ Glycated haemoglobin; hs-CRP=High-sensitivity C-reactive protein; $\mathrm{SD}=$ Standard deviation; $\mathrm{DM}=$ Diabetes mellitus.

\section{Correlation between Vitamin D Level and Age, BMI, Disease Duration, HbAIC and ACR}

It was observed that VD and age $(r=0.356 ; P=0.043)$ were significantly correlated in positive manner while VD was negatively correlated with $\mathrm{BMI}(r=-0.522 ; P=0.008)$, duration of disease $(r=-0.499 ; P=0.004)$, ACR ( $r=-0.376$; $P=0.016)$ and HbA1c $(r=-0.326 ; P=0.031)$.

\section{Discussion}

The observation of characteristics is that T2DM is more common in females, overweight, and most subjects were with physically inactive, uncontrolled blood sugar levels and less sun exposure. In this study it was found that there is high occurrence of VD insufficiency $(78.5 \%)$ in 
our participants. Similar findings were also there in some previous studies on diabetics and non-diabetics. ${ }^{13} \mathrm{Few}$ other researches, supports that female sex is an independent indicator of VD deficiency. ${ }^{14}$ So, speculated to a number of causes could lead to VD insufficiency, like physical activity, nutrition and spending more indoor times. Females had more hs-CRP in comparison to males in current research which supports previous studies. ${ }^{15,16}$

Table 2.Nonparametric association of study variables in groups classified according to Vitamin D status

\begin{tabular}{|c|c|c|c|c|c|}
\hline S. No. & Parameters & \% Frequency VD Deficient & \% Frequency VD Sufficient & OR/Cl & P-values \\
\hline 1. & Male & $38.7 \%(309)$ & $71.10 \%(161)$ & $3.89(1.89-7.98)$ & $<0.001$ \\
\hline 2. & Female & $61.3 \%(490)$ & $28.9 \%(65)$ & & \\
\hline 3. & $<55$ years age & $49 \%(392)$ & $34.09 \%(88)$ & $1.86(0.92-3.73)$ & 0.055 \\
\hline 4. & $>55$ years age & $51 \%(408)$ & $65.91 \%(137)$ & & \\
\hline 5. & Normal weight & $19 \%(152)$ & $40.4 \%(80)$ & & \\
\hline 6. & Overweight & $45.5 \%(364)$ & $42.6 \%(78)$ & $5.97(1.79-19.79)$ & 0.004 \\
\hline 7. & obese & $40.50 \%(324)$ & $17 \%(27)$ & $2.24(0.76-6.59)$ & 0.144 \\
\hline 8. & Controlled sugar & $31 \%(248)$ & $36.36 \%(82)$ & $0.78(0.39-1.58)$ & 0.312 \\
\hline 9. & Uncontrolled sugar & $69 \%(552)$ & $63.64 \%(143)$ & & \\
\hline 10. & Do exercise & $44.65 \%(357)$ & $56.52 \%(124)$ & $0.62(0.32-120)$ & 0.106 \\
\hline 11. & No exercise & $55.35 \%(442)$ & $43.48 \%(102)$ & & \\
\hline 12. & $<5$ hours exercise & $91.30 \%(730)$ & $75 \%(163)$ & $3.5(1.45-8.39)$ & 0.006 \\
\hline 13. & $>5$ hours exercise & $8.7 \%(69)$ & $25 \%(63)$ & & \\
\hline
\end{tabular}

Categorical variables reported as frequencies and percentage. Chi-square and multiple regression tests have been done to compare between variables. BMI: Body Mass Index; OR: Odd Ratio; Cl: Confidence Interval, VD: Vitamin D.

Table 3.Study parameters in patients group classified according to Vitamin D status, gender, sun exposure, physical exercise, and glycemic control

\begin{tabular}{|c|c|c|c|c|}
\hline & \multicolumn{4}{|c|}{ Study parameters in case group classified according to VD status } \\
\hline S. No. & Parameters & VD deficient (mean $\pm S D)$ & VD sufficient (mean $\pm S D$ ) & $\mathbf{p}$ \\
\hline 1. & HbA1c (\%) & $9.46 \pm 2.43$ & $8.82 \pm 2.63$ & 0.159 \\
\hline 2. & hsCRP mg/l & $4.24 \pm 4.11$ & $2.72 \pm 2.61$ & 0.007 \\
\hline \multirow[t]{3}{*}{3.} & ACR mg/g & $47.8 \pm 117$ & $19.9 \pm 22.7$ & 0.001 \\
\hline & \multicolumn{4}{|c|}{ Patients classified according to sex } \\
\hline & Parameters & Male (mean $\pm S D)$ & Female (mean \pm SD) & $\mathbf{p}$ \\
\hline 1. & Vitamin D (ng/ml) & $30.2 \pm 12.2$ & $20.0 \pm 8.90$ & $<0.001$ \\
\hline 2. & hsCRP mg/l & $3.54 \pm 2.55$ & $5.91 \pm 2.61$ & 0.004 \\
\hline \multirow[t]{3}{*}{3.} & ACR mg/g & $30.6 \pm 8.60$ & $42.9 \pm 7.21$ & 0.269 \\
\hline & \multicolumn{4}{|c|}{ Patients classified according to sun exposure } \\
\hline & Parameters & Sun exposure $<5 \mathrm{~h} /$ day (mean $\pm \mathrm{SD}$ ) & Sun exposure $>5 \mathrm{~h} /$ day (mean $\pm S D$ ) & $\mathbf{p}$ \\
\hline 1. & Vitamin D (ng/ml) & $23.6 \pm 11.2$ & $32.8 \pm 12.3$ & 0.001 \\
\hline 2. & hsCRP mg/l & $5.15 \pm 6.48$ & $2.81 \pm 1.91$ & $<0.001$ \\
\hline \multirow[t]{3}{*}{3.} & ACR mg/g & $38.6 \pm 6.33$ & $24.0 \pm 5.79$ & 0.09 \\
\hline & \multicolumn{4}{|c|}{ Patients classified according to physical exercise } \\
\hline & Parameters & $\begin{array}{l}\text { Patients with physical exercise } \\
\text { (mean } \pm \text { SD) }\end{array}$ & $\begin{array}{l}\text { Patients without physical exercise } \\
\text { (mean } \pm \text { SD) }\end{array}$ & $\mathbf{p}$ \\
\hline 1. & Vitamin D (ng/ml) & $27.0 \pm 12.4$ & $23.3 \pm 11.0$ & 0.045 \\
\hline
\end{tabular}




\begin{tabular}{|c|c|c|c|c|}
\hline 2. & hsCRP mg/l & $4.29 \pm 5.35$ & $5.20 \pm 6.91$ & 0.31 \\
\hline 3. & ACR mg/g & $21.1 \pm 41.5$ & $48.6 \pm 77.4$ & 0.002 \\
\hline & \multicolumn{4}{|c|}{ Patients classified according to glycemic control } \\
\hline & Parameters & Controlled DM (mean \pm SD) & Uncontrolled DM (mean $\pm S D$ ) & p \\
\hline 1. & Vitamin D $(\mathrm{ng} / \mathrm{ml})$ & $25.7 \pm 11.4$ & $24.3 \pm 11.9$ & 0.463 \\
\hline 2. & hsCRP mg/l & $4.06 \pm 2.63$ & $5.12 \pm 2.65$ & 0.266 \\
\hline 3. & ACR mg/g & $20.6 \pm 6.59$ & $43.8 \pm 7.21$ & 0.018 \\
\hline
\end{tabular}

In addition, physical exercise and exposure to sunrays significantly raises VD and lowers hs-CRP values. Current research findings confirmed by previous results, indicating that lower values of duration of sun exposure and physical inactivity significantly affects VD levels in the body. Physical exercise may raise serum values of VD by increasing skin exposure to sunrays, ${ }^{17}$ more lipolysis and increasing mobilization of stored VD from the fat compartments. ${ }^{18}$

Concurrent with prior studies, the current research resulted that subjects with type 2 diabetes mellitus having VD deficiency had raised values of hs-CRP in comparison to those with VD sufficieny. The previous researches has reported that VD deficiency may lead to systemic inflammation, ${ }^{19}$ because VD prevents the formation of inflammatory markers like interleukin 2 (IL-2), interferongamma and IL-5 through Th-1 lymphocytes, and it also prevents the formation of IL- 6 by monocytes, as it is the first stimulant of hs-CRP generation. ${ }^{7} \mathrm{VD}$ deficiency causes macrovascular and microvascular complications by causing inflammation of the vessels. ${ }^{1}$

Here we find that the mean ACR was significantly raised in diabetic with VD deficiency than those with VD sufficient. Moreover, the reciprocal relation of ACR and VD was established. These results were incompatible with prior results that subjects with type 2 diabetes mellitus had higher values of ACR; on the other side, VD supplementation decreases ACR. ${ }^{6}$ ACR is an early marker for nephropathy, and VD function as proteinuria homeostasis ${ }^{20}$ hence VD deficiency is linked with nephropathy in T2DM subjects. Physical activity significantly reduces ACR values. Prior reports signify same results of physical activity link with decreased albumin excretion in the T2DM patients despite unknown mechanism of exercise on ACR; possibly it is because of its action on the vascular endothelium that is due to nitric oxide acting as vaso-relaxant. ${ }^{21}$

This research aims to compare mean VD values of uncontrolled diabetes with that of controlled. Although there was an insignificant difference was observed, yet, it favours with prior studies showing insignificant differences in mean $\mathrm{HbA1c}$ between groups of VD status. ${ }^{19}$ Likewise, Pearson's regression analyses resulted that $\mathrm{VD}$ and $\mathrm{HbA} 1 \mathrm{c}$ are negatively correlated. As VD enhances pancreatic $\beta$-cell secretion of insulin and activation from proinsulin to insulin, it might help in insulin function by simulating the insulin receptors expression and control of the calcium level. ${ }^{22}$ So, VD must be known for blood sugar homeostasis and hence complications of diabetes.

Actually, VD values are negatively associated with BMI, disease duration, and sugar control. ${ }^{2}$ In other researches, there was significant relation of VD deficiency and albuminuria, and we could calculate low VD level on nephropathy development. ${ }^{23}$ Also, study on drug trial proved reduction of proteinuria after the administration of VD in patients with Type 2 diabetes. ${ }^{24}$

The drawbacks of this study were investigating some haematological parameters related to VD control like phosphorus, parathyroid hormone and calcium values. The major drawback of current research was that subjects were selected on the basis of their previous clinical data, and no pre investigations were done to diminish confounding factors of drawback.

\section{Conclusion}

In this study we concluded that the number of VD deficiency in our population is more. ACR and hs-CRP are raised in type 2 diabetics with VD $<30 \mathrm{ng} / \mathrm{ml}$. Moreover, VD values were negatively related with $\mathrm{BMI}$, duration of disease, $A C R$, and HbA1c values. As a result, VD deficiency may cause nephropathy in patients of Type 2 diabetes mellitus. Therefore, investigating and VD administration should be done.

\section{Acknowledgement}

Authors are grateful to all patients, clinicians and other medical staffs involved in this study.

\section{Conflicts of Interest: None}

\section{References}

1. Mao L, Ji F, Liu Y et al. Calcitriol plays a protective role in diabetic nephropathy through antiinflammatory effects. Int J Clin Exp Med 2014; 7: 5437-44. Available From: https://www.researchgate. net/publication/272097445_Calcitriol_plays_a_ protective_role_in_diabetic_nephropathy_through_ anti-inflammatory_effects. [Google Scholar, PubMed]. 
2. Ahmadieh H, Azar ST, Lakkis N, et al. Hypovitaminosis $\mathrm{d}$ in patients with type 2 diabetes mellitus: A relation to disease control and complications. ISRN Endocrinol 2013; 2013: 641098. [PubMed/ Google Scholar].

3. Kulie T, Groff A, Redmer J et al. Vitamin D: An evidence-based review. J Am Board Fam Med 2009; 22: 698-706. Available From: https://www.jabfm.org/ content/22/6/698. [Google Scholar, PubMed].

4. Long M, Wang C, Liu D. Glycated hemoglobin A1C and Vitamin $D$ and their association with diabetic retinopathy severity. Nutr Diabetes 2017; 7: e281. Available From: https://www.semanticscholar.org/ paper/Glycated-hemoglobin-A1C-and-vitamin-D-andtheir-Long-Wang/6fa3eb25c4ed126716a655679ffb4f 26df866120. [Google Scholar/ PubMed].

5. Alcubierre N, Valls J, Rubinat E et al. Vitamin D deficiency is associated with the presence and severity of diabetic retinopathy in type 2 diabetes mellitus. J Diabetes Res 2015; 2015: 374178. Available From: https://www. hindawi.com/journals/jdr/2015/374178/. [Google Scholar/ PubMed].

6. Nakashima A, Yokoyama K, Yokoo T et al. Role of Vitamin $D$ in diabetes mellitus and chronic kidney disease. World J Diabetes. 2016; 7: 89-100. Available From: https:// www.ncbi.nlm.nih.gov/pmc/articles/PMC4781904/ [Google Scholar/ PubMed].

7. Liefaard MC, Ligthart S, Vitezova A et al. Vitamin D and C-reactive protein: A mendelian randomization study. PLoS One. 2015; 10: e0131740. Available From: https:// journals.plos.org/plosone/article/figure?id=10.1371/ journal.pone.0131740.g002. [Google Scholar/ PubMed].

8. Mandarino NR, Júnior FD, Salgado JV et al. Is Vitamin D deficiency a new risk factor for cardiovascular disease? Open Cardiovasc Med J 2015; 9: 40-9. Available From: https://www.ahajournals.org/doi/10.1161/ CIRCULATIONAHA.107.706127. [Google Scholar/ PubMed].

9. Lee JH, O'Keefe JH, Bell D et al. Vitamin D deficiency an important, common, and easily treatable cardiovascular risk factor? J Am Coll Cardio/ 2008; 52: 1949-56. Available From: https://www.sciencedirect.com/science/article/ pii/S0735109708031756 [Google Scholar/ PubMed].

10. Yousif NM, Ismail AM. Alanine aminotransferase and gamma-glutamyl transferase activity as predictor markers for hepatocellular damage in Vitamin D deficient type 2 diabetes mellitus patients-crosssectional study. Am J Med Med Sci 2014; 4: 18691.Available From: https://www.researchgate.net/ publication/274632736_Alanine_Aminotransferase_ and_Gamma-glutamyltransferase_Activity_as_ Predictor_Markers_for_Hepatocellular_Damage_in_ Vitamin_D_Deficient_Type_2_Diabetes_Mellitus_
Patients_-_Cross-sectional_Study. [Google Scholar].

11. Shaafie IA, Hesham RA, Basha AA. Vitamin D status in type 2 diabetic patients and its association with glycemic control, lipids \& microalbuminuria: $A$ pilot study. GMJ, ASM 2013; 2(S1): S6-13. Available From: https://pdfs.semanticscholar.org/8faf/ b3a972b5292b6d393313b92c9c760bc179b5.pdf. [Google Scholar].

12. Tiryaki Ö, Usalan C, Sayiner ZA. Vitamin D receptor activation with calcitriol for reducing urinary angiotensinogen in patients with type 2 diabetic chronic kidney disease. Ren Fail 2016; 38: 222-227. Available From: https://www.tandfonline.com/doi/full/10.3109 /0886022X.2015.1128250. [Google Scholar/ PubMed].

13. Rafiq $S$, Jeppesen PB. Body mass index, Vitamin D, and type 2 diabetes: A Systematic review and meta-analysis. Nutrients. 2018; 10: pii-E1182. Available From: https:// www.researchgate.net/publication/327277096_Body_ Mass_Index_Vitamin_D_and_Type_2_Diabetes_A_ Systematic_Review_and_Meta-Analysis [Google Scholar/ PubMed].

14. Rolim MC, Santos BM, Conceição G et al. Relationship between Vitamin D status, glycemic control and cardiovascular risk factors in Brazilians with type 2 diabetes mellitus. Diabetol Metab Syndr 2016; 8: 77. Available From: https://www.researchgate.net/ publication/310471063_Relationship_between_ Vitamin_D_status_glycemic_control_and_ cardiovascular_risk_factors_in_Brazilians_with_ type_2_diabetes_mellitus. [Google Scholar/PubMed].

15. Qasim AN, Budharaju V, Mehta NN et al. Gender differences in the association of C-reactive protein with coronary artery calcium in type-2 diabetes. Clin Endocrinol (Oxf) 2011; 74: 44-50. Available From: https://www.researchgate.net/publication/46577152 Gender_Differences_in_the_Association_of_CReactive_Protein_with_Coronary_Artery_Calcium_ in_Type-2_Diabetes. [Google Scholar PubMed].

16. Mahajan A, Tabassum R, Chavali S et al. High-sensitivity C-reactive protein levels and type 2 diabetes in urban North Indians. J Clin Endocrinol Metab 2009; 94: 21232127. Available From: https://academic.oup.com/ jcem/article/94/6/2123/2597228. [Google Scholar/ PubMed].

17. Almehmadi B, Fallata $E$, Alqahtani S, et al. The effects of physical activity and sun exposure on Vitamin D status among children from Jeddah, Saudi Arabia. J Pediatr Care 2016; 2: 1-4. Available From: http://pediatrics. imedpub.com/the-effects-of-physical-activity-and-sunexposure-on-vitamin-d-status-among-children-fromjeddah-saudi-arabia.php?aid=8822/. [Google Scholar].

18. Kavadar G, Demircioğlu DT, Özgönenel L et al. The relationship between Vitamin $D$ status, physical 
activity and insulin resistance in overweight and obese subjects. Bosn J Basic Med Sci 2015; 15: 6266. Available From: https://www.researchgate.net/ publication/277780100_The_relationship_between_ vitamin_D_status_physical_activity_and_insulin_ resistance_in_overweight_and_obese_subjects. [Google Scholar/ PubMed].

19. Haidari F, Zakerkish M, Karandish M et al. Association between serum Vitamin D level and glycemic and inflammatory markers in non-obese patients with type 2 diabetes. Iran J Med Sci 2016; 41: 367-373. Available From: https://www.researchgate.net/ publication/307576913_Association_between_Serum_ Vitamin_D_Level_and_Glycemic_and_Inflammatory_ Markers_in_Non-obese_Patients_with_Type_2_ Diabetes. [Google Scholar/ PubMed].

20. Prabhu RA, Saraf K. Vitamin D in diabetic nephropathy. J Postgrad Med 2018; 64: 5-6. Available From: https:// www.ncbi.nlm.nih.gov/pmc/articles/PMC5820815/.

21. Robinson ES, Fisher ND, Forman JP et al. Physical activity and albuminuria. Am J Epidemiol 2010; 171: 515-521. Available From: https://www.ncbi.nlm.nih.gov/pmc/ articles/PMC2842220/ [Google Scholar].

22. Swamy M, Ganiger A, Prasad SD et al. Serum 25-hydroxy Vitamin D levels in type 2 diabetes mellitus - A comparative study. Int J Clin Biochem Res 2016; 3: 255-258. [Google Scholar].

23. Zoppini G, Galletti A, Targher G et al. Lower levels of 25-hydroxyvitamin D3 are associated with a higher prevalence of microvascular complications in patients with type 2 diabetes. BMJ Open Diabetes Res Care 2015;3:e000058. Available From: https://www. researchgate.net/publication/275663635_Lower_ levels_of_25-hydroxyvitamin_D3_are_associated_ with_a_higher_prevalence_of_microvascular_ complications_in_patients_with_type_2_diabetes [Google Scholar/ PubMed].

24. Momeni A, Mirhosseini M, Kabiri M et al. Effect of Vitamin D on proteinuria in type 2 diabetic patients. $J$ Nephropathol. 2017; 6: 10-14. Available From: https:// www.ncbi.nlm.nih.gov/pmc/articles/PMC5106877/ [Google Scholar]. 